\title{
A Quantitative Comparison of the Precipitation Behavior of Lignin from Sweetgum and Pine Kraft Black Liquors
}

\author{
Juliana M. Jardim, ${ }^{\mathrm{a}}$ Peter W. Hart, ${ }^{\mathrm{b}, *}$ Lucian Lucia, ${ }^{\mathrm{a}}$ Hasan Jameel, ${ }^{\mathrm{a}}$ and Houmin Chang ${ }^{\mathrm{a}}$ \\ Lignin is a by-product of the pulp and paper industry that can be precipitated by \\ acidification from black liquor as a potential feedstock for valuable green materials. \\ Precipitation and quantification of lignin from softwood black liquors have been \\ documented and commercialized with well-established methods; however, \\ applying those methods to the precipitation of lignin from hardwood black liquors \\ has produced low lignin yields. A need to understand the main differences \\ between hardwood and softwood lignin precipitation prompted the current \\ investigation. Multiple black liquor samples from sweetgum and pine pulping were \\ obtained at different times of standard kraft cooks. Two lignin fractions were \\ precipitated from each of these black liquors, one at $\mathrm{pH} 9.5$ and one at $\mathrm{pH} 2.5$. \\ Detailed lignin and carbohydrate material balances were performed around each \\ of the sample sets, starting with the wood and ending with precipitated lignin \\ fractions. For all conditions tested, the amount and purity of pine lignin precipitated \\ were superior to sweetgum lignin. The maximum recovery for sweetgum lignin \\ was $69.7 \%$, while for pine lignin, it was $90.9 \%$.
}

Keywords: Lignin; Precipitation; Material balance; Purity; Hardwood; Pinus taeda; Liquidambar styraciflua

Contact information: a: Department of Forest Biomaterials, North Carolina State University, 2820 Faucette Drive, Campus Box 8005, Raleigh, North Carolina 27695 USA; b: WestRock, 501 South $5^{\text {th }}$ Street, Richmond, VA 23219 USA; *Corresponding author: peter.hart@westrock.com

\section{INTRODUCTION}

Kraft (or sulfate) pulp mills account for around two-thirds of the global pulping capacity (Magdeldin and Järvinen 2020). The kraft process is based on the application of sodium hydroxide $(\mathrm{NaOH})$ and sodium sulfide $\left(\mathrm{Na}_{2} \mathrm{~S}\right)$ to wood chips, under pressure and relatively high temperatures (150 to $170{ }^{\circ} \mathrm{C}$ ), which targets lignin fragmentation/ hydrolysis, dissolution, and subsequent fiber liberation while retaining the majority of the carbohydrates in a fibrous form. The process generates a residual process stream (spent liquor/black liquor) that is rich in organic degradation products (lignin and carbohydrates) and spent inorganics (e.g., sulfides, sulfates, carbonates, hydroxides). Typically, this black liquor is subjected to a recovery system in which it is evaporated to a high solids content of 65 to $72 \mathrm{wt} \%$ and then combusted to smelt in a recovery boiler to recover the original chemicals $\left(\mathrm{NaOH}\right.$ and $\left.\mathrm{Na}_{2} \mathrm{~S}\right)$ with the concomitant production of steam and power from the dissolved organics.

Many recovery boilers are limited by total solids loading or steam generation (circulation limit), and hence they represent the capacity-limiting step in several pulp mills. Lignin isolation from black liquor is considered a potential method for reducing these process limitations (Öhman et al. 2007). In fact, the creation of new economic downstream uses for the black liquor enables greater pulp production and an increase in total revenue (Zhu et al. 2014; Klett 2017) since the recovered lignin can serve as a feedstock for biomaterials and biochemicals.

Jardim et al. (2020). "Lignin precipitation: HW vs. SW," BioResources 15(3), 5464-5480. 5464 
Lignin is produced at large scale: approximately 78 million tons are generated globally each year by kraft pulp mills (Miller et al. 2016). Additionally, research efforts also use lignin precipitation as a method to obtain selected, purified samples for lignin component analysis.

Lignin is a complex biopolymer biosynthesized by repetitive dehydrogenation and cross-coupling of three major phenylpropanoid (C6-C3) units, namely, sinapyl alcohol, coniferyl alcohol, and p-coumaryl alcohol; forming syringylpropane (S), guaiacylpropane $(\mathrm{G})$, and $p$-hydroxyphenylpropane $(\mathrm{H})$ units in lignin (Lin and Dence 1992). These structural building blocks are zipped together by ether linkages and carbon-carbon bonds (Alén 2000).

Although the chemical structure of lignin has been extensively investigated by both wet chemical and spectroscopic methods, its structural complexity has never been fully elucidated (Ralph et al. 2004). However, it is well known that the structural characteristics of lignin from hardwoods and softwoods profoundly differ from each other. Guaiacyl lignin is typically found in softwoods and appears to vary little amongst species (Sarkanen et al. 1967; Akiyama et al. 2005). Guaiacyl-Syringyl lignin is typically found in hardwoods, and the $\mathrm{S}$ to $\mathrm{G}$ ratio tends to vary greatly between species (Santos et al. 2012).

Lignin properties depend on feedstock from which they are obtained, the extraction method employed, and downstream purification processes (dos Santos et al. 2014). LignoBoost and LignoForce processes are the two main commercial technologies for precipitating lignin from spent liquors (Dessbesell et al. 2020). LignoBoost is an industrial process that uses dissolved carbon dioxide $\left(\mathrm{CO}_{2}\right)$ to decrease the $\mathrm{pH}$ of the process stream from approximately 13 to 10 . "LignoForce" is another commercialized technology that first oxidizes the black liquor with oxygen $\left(\mathrm{O}_{2}\right)$ and then acidifies to around $\mathrm{pH} 9$ with $\mathrm{CO}_{2}$ (Fatehi and Chen 2016). It is known that when the black liquor is acidified, the phenoxide groups of the dissolved lignin become protonated, and lignin solubility decreases, i.e., the lignin precipitates. After precipitation, the solids are separated by filtration and subsequently resuspended in water and sulfuric acid $\left(\mathrm{H}_{2} \mathrm{SO}_{4}\right)$ to obtain a lower $\mathrm{pH}$ of about 2.5 to remove impurities (Wallmo et al. 2016).

The bulk of the work on lignin precipitation from kraft black liquor has been performed on softwood, while very little has been published about hardwood black liquors (Zhu et al. 2014). It was initially thought that the lignin precipitation methods developed and proven to work for the majority of softwood species would be acceptable for hardwood species. However, investigations into various hardwood lignin compositions have used the softwood precipitation techniques and obtained unexpectedly low lignin yields (Santos et al. 2011, 2012; Kumar et al. 2016; Gomes et al. 2018; Giummarella et al. 2019). Lack of understanding of hardwood lignin precipitation is a significant hurdle toward fully characterizing and utilizing this raw material, which prompted this study.

The current work aimed at establishing a material balance over the kraft pulping process and lignin precipitation from hardwood and softwood black liquors obtained at different pulping extents. Quantification of lignin recovery was also intended. Thus, two fractions of sweetgum lignin were precipitated from black liquor at distinct $\mathrm{pHs}(\mathrm{pH} 9.5$ and 2.5), and a baseline comparison between these lignins and pine lignins was accomplished. The impact of $\mathrm{H}$-factor on yield and purity of precipitated lignins was also investigated. 


\section{EXPERIMENTAL}

\section{Materials}

Southern sweetgum (Liquidambar styraciflua), a hardwood, and Southern pine (Pinus taeda), a softwood, were the samples investigated. Wood logs were processed into chips and screened according to the standard method "Size distribution" (SCAN-CM 40:01, 2001).

\section{Methods}

Kraft pulping

Kraft pulping experiments were carried out in a $10 \mathrm{~L}$ laboratory pulping digester (Greenwood Instruments, LLC; Andover, MA, USA) equipped with a temperature controller, liquor recirculation piping, and an indirect heating system. The general cooking conditions are shown in Table 1. Batch cooks were performed using $1000 \mathrm{~g}$ oven-dried (O.D.) chips. Pulped chips were placed in a stainless-steel box equipped with a 150-mesh screen, washed thoroughly with water, and disintegrated. The washed pulp was then centrifuged to approximately $30 \%$ consistency and subsequently stored in polyethylene bags for follow-up characterization. Pulp yield was gravimetrically determined. The black liquor was collected and characterized according to the protocols "Solids Content of Black Liquor" (TAPPI/ANSI T650 om-15) and "Residual Alkali" (SCAN-N 33:94). The black liquor samples were stored in sealed Nalgene bottles for lignin precipitation.

Table 1. Kraft Pulping Conditions

\begin{tabular}{|c|c|c|}
\hline Parameter & $\begin{array}{c}\text { Hardwood } \\
\text { (Sweetgum) }\end{array}$ & $\begin{array}{c}\text { Softwood } \\
\text { (Pine) }\end{array}$ \\
\hline Liquor/Wood ratio & $4 / 1$ & $4 / 1$ \\
\hline Effective Alkali as $\mathrm{Na}_{2} \mathrm{O}(\%)$ & 16 & 19 \\
\hline Sulfidity $(\%)$ & 25 & 25 \\
\hline Temperature $\left({ }^{\circ} \mathrm{C}\right)$ & 160 & 170 \\
\hline
\end{tabular}

Pulping runs were done at 30, 60, 90, 120, and 150 min to obtain different $\mathrm{H}$-factors covering an entire typical bleachable grade cook. All other pulping conditions remained constant (Table 1). H-factor and pulping temperature at the time of sampling are shown in Fig. 1 for both the sweetgum and pine cooks. Each raw material generated five pulp samples and five black liquor samples. A sample of pure wood chips was also collected.

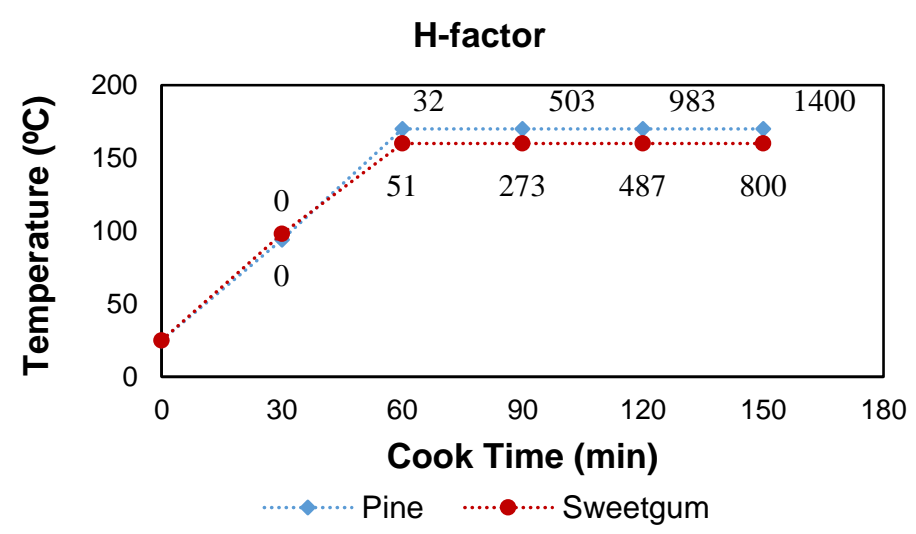

Fig. 1. H-factor of each sample for the sweetgum and pine cooks 


\section{Lignin precipitation}

Collected black liquor samples were filtered over Whatman \#3 filter paper to remove fines. Filtered black liquors were evaporated to a solids content of approximately $20 \%$ and used for precipitation experiments of two lignin fractions ( $\mathrm{pH} 9.5$ and 2.5). Concentrated black liquors were sparged with $\mathrm{CO}_{2}$ at a low flow rate to attain a $\mathrm{pH}$ of 9.5. The concentrated mixtures were allowed to equilibrate over $30 \mathrm{~min}$. The precipitated materials were isolated from the liquors through centrifugation, and the supernatants were stored for further precipitation. The solids were washed with hydrochloric acid $(\mathrm{HCl})$ to remove ash at $\mathrm{pH} 2.5$ and subsequently washed with acetic acid to remove residual $\mathrm{HCl}$ at $\mathrm{pH}$ 3.5. After washing steps, the solids were isolated by centrifugation, suspended in deionized water, and freeze-dried. Typically, precipitated lignin is washed with $\mathrm{H}_{2} \mathrm{SO}_{4}$; however, in this work, washing was performed with $\mathrm{HCl}$ because it is reported to improve ash removal compared to sulfuric acid (dos Santos et al. 2014). Washing with acetic acid was carried out to remove residual $\mathrm{HCl}$ because it is less harmful to the freeze-drier vacuum pump compared to $\mathrm{HCl}$. These solids, called lignin fraction at $\mathrm{pH} 9.5$, were obtained according to commercially known lignin isolation protocols (e.g., LignoBoost).

The supernatants after carbonation were further acidified with $6 \mathrm{~N} \mathrm{HCl}$ to $\mathrm{pH} 2.5$ in order to precipitate a second lignin fraction, which was also washed with $\mathrm{HCl}$, acetic acid, and freeze-dried. These solids were called lignin fraction at $\mathrm{pH} 2.5$ and were obtained with the understanding that at $\mathrm{pH} 2.5$, all remaining lignin or most of it would be precipitated.

Precipitation experiments were performed at room temperature, atmospheric pressure, and constant stirring. A schematic representation of the precipitation and purification processes is shown in Fig. 2.

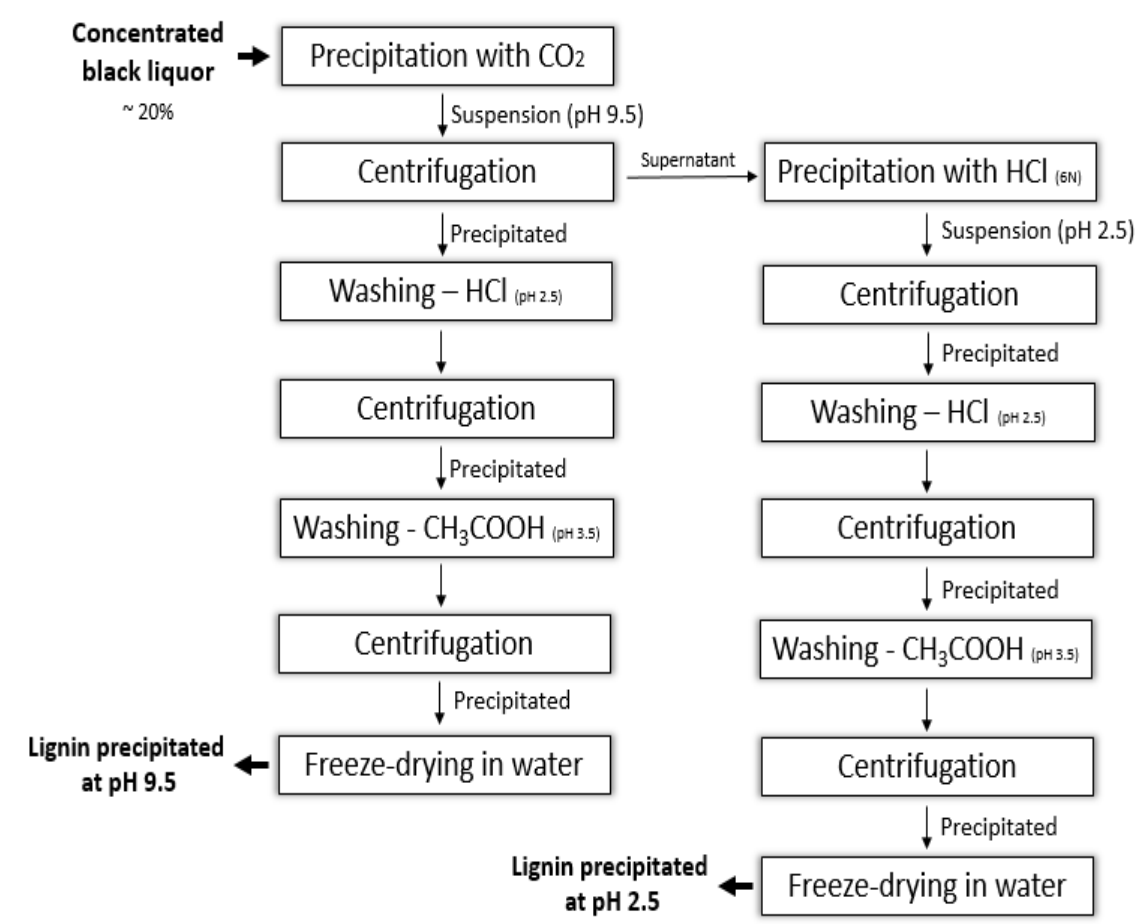

Fig. 2. Schematic representation of the protocol used for lignin precipitation from kraft black liquor of two lignin fractions: $\mathrm{pH} 9.5$ and $\mathrm{pH} 2.5$ 
The influence of $\mathrm{pH}$, ionic strength, temperature, agitation speed, solids content, and atmosphere on precipitation have been well studied and reported before (Howell and Thring 2000; García et al. 2009; Wallmo et al. 2009; Theliander 2010; dos Santos et al. 2014; Zhu et al. 2014; Helander et al. 2016; Durruty et al. 2017; Sewring et al. 2019). The experimental conditions applied to sweetgum and pine black liquors in the present investigation were chosen to establish a fair comparison between the behavior of both lignins over precipitation.

\section{Characterization of wood, pulp, and precipitated lignin}

The wood chips were ground in a Wiley mill. The resulting milled wood was screened, and the fraction, which passed through a 40-mesh screen and was retained on a 60-mesh screen was kept for analyses. The milled wood was extracted in a Soxhlet apparatus for $6 \mathrm{~h}$ using a benzene-ethanol mixture (2:1 v/v ratio) (TAPPI Standard Test Method T 264 cm-07 "Preparation of wood for chemical analysis"). Carbohydrates and lignin contents were quantified according to the Technical Report NREL/TP-510-42618 "Determination of structural carbohydrates and lignin in biomass." Ash content was measured according to "Ash in wood, pulp, paper and paperboard: combustion at $525{ }^{\circ} \mathrm{C}$ " (TAPPI Standard Test Method T 211 om-16). The same protocols were applied to the characterization methods for the lignin samples precipitated from the black liquors.

\section{Material balance}

Table 2 shows the template used for the material balance calculations.

Table 2. Material Balance of the Lignin Isolation from Sweetgum Black Liquor at 60 Min. Balance Assumes 100 O.D. g of Wood as the Starting Material

\begin{tabular}{|l|c|c|c|c|c|c||}
\hline \multirow{2}{*}{ Sample Location } & \multicolumn{2}{c|}{ Inputs (g) } & \multicolumn{2}{c|}{ Intermediates (g) } & \multicolumn{2}{c|}{ Outputs (g) } \\
\cline { 2 - 8 } & Carbs & Lignin & Carbs & Lignin & Carbs & Lignin \\
\hline \hline Wood Chips & 64.5 & 25.9 & --- & --- & --- & --- \\
\hline Pulp & --- & --- & --- & --- & 47.7 & 10.8 \\
\hline Black Liquor & --- & --- & --- & --- & 16.8 & 15.1 \\
\hline \hline Black Liquor & 16.8 & 15.1 & --- & --- & --- & --- \\
\hline $\begin{array}{l}\text { Supernatant from } \mathrm{CO}_{2} \\
\text { Precipitation }\end{array}$ & --- & --- & 15.1 & 12.0 & --- & --- \\
\hline $\begin{array}{l}\text { Supernatant from HCl } \\
\text { Precipitation }\end{array}$ & --- & --- & 14.8 & 8.8 & --- & --- \\
\hline Lignin @ pH 9.5 & --- & --- & --- & --- & 1.7 & 3.1 \\
\hline Lignin @ pH 2.5 & --- & --- & --- & --- & 0.4 & 3.2 \\
\hline \hline \% Recovery from Black Liquor & --- & --- & --- & --- & $\mathbf{1 2 . 2}$ & $\mathbf{4 1 . 8}$ \\
\hline
\end{tabular}

The starting wood chips were used as the input materials for the pulping process, while pulp and black liquor were the outputs. For the precipitation experiments, black liquors were the input, whereas the solids isolated were the outputs of the system. Solid and liquid flows were accounted for in order to determine lignin recovery (yield) over precipitation experiments. The calculations were based on the compositional analysis of wood, pulp, and solids precipitated from black liquor. In addition, the volume of white liquor and solids from the chemicals added to the pulping process were taken into 
consideration. The data in Table 2 were obtained for sweetgum pulp and liquor after 60 min of cooking time (51 H-factor).

The amounts of carbohydrates and lignin in the sweetgum wood chips were $64.5 \mathrm{~g}$ and $25.9 \mathrm{~g}$, respectively. After $60 \mathrm{~min}$ of pulping (at $\mathrm{H}$-factor 51), the residual carbohydrates mass was $47.7 \mathrm{~g}$, whereas the residual lignin mass was $10.8 \mathrm{~g}$. The determination of carbohydrate and lignin contents in the wood and in the produced pulp allowed calculation of the amount of carbohydrates and lignin dissolved in the black liquor. Therefore, at an H-factor of 51, the amount of carbohydrates in the black liquor was 16.8 $\mathrm{g}(64.5 \mathrm{~g}-47.4 \mathrm{~g})$, and the amount of lignin was $15.1 \mathrm{~g}(25.9 \mathrm{~g}-10.8 \mathrm{~g})$. These values were used as inputs to calculate carbohydrate and lignin recovery.

After precipitation of both lignin fractions ( $\mathrm{pH} 9.5$ and 2.5), the solids isolated were characterized, and the values obtained were the outputs shown in the bottom part of Table 2. In the example, the lignin fraction isolated at $\mathrm{pH} 9.5$ represented $1.7 \mathrm{~g}$ of carbohydrates and $3.1 \mathrm{~g}$ of lignin. In contrast, the lignin fraction obtained at $\mathrm{pH} 2.5$ represented $0.4 \mathrm{~g}$ of carbohydrates and $3.2 \mathrm{~g}$ of lignin. The intermediate values were obtained by a simple subtraction of each compound dissolved in the black liquor minus the amount obtained in each step of the precipitation. Finally, the recovery of each compound (carbohydrates and lignin) was calculated based on its amount in the black liquor and in the solids precipitated.

\section{RESULTS AND DISCUSSION}

\section{Pulping}

The present work evaluated pulp and black liquor samples of hardwood (sweetgum) and softwood (pine) at different points of kraft pulping. The cooks were performed to different levels by varying $\mathrm{H}$-factor. Pulping results for sweetgum and pine are shown in Table 3.

Table 3. Pulping Results for Sweetgum and Pine: H-Factor, Pulp Yield, Residual Effective Alkali (rEA), and Percent of Solids in the Black Liquor

\begin{tabular}{|c|c|c|c|c|c|c|c|c|}
\hline \multirow{2}{*}{$\begin{array}{c}\text { Cook } \\
\text { Time } \\
(\text { min) }\end{array}$} & \multicolumn{4}{|c|}{ Sweetgum } & \multicolumn{4}{c|}{ Pine } \\
\cline { 2 - 9 } & H-factor & $\begin{array}{c}\text { Pulp } \\
\text { Yield (\%) }\end{array}$ & $\begin{array}{c}\text { rEA } \\
(\mathrm{g} / \mathrm{L})\end{array}$ & $\begin{array}{c}\text { Solids in } \\
\text { BL }(\%)\end{array}$ & $\begin{array}{c}\mathrm{H} \\
\text { Factor }\end{array}$ & $\begin{array}{c}\text { Pulp } \\
\text { Yield (\%) }\end{array}$ & $\begin{array}{c}\text { rEA } \\
(\mathrm{g} / \mathrm{L})\end{array}$ & $\begin{array}{c}\text { Solids in } \\
\text { BL (\%) }\end{array}$ \\
\hline 30 & 0 & 85.5 & 12.5 & 8.9 & 0 & 93.2 & 19.2 & 11.1 \\
\hline 60 & 51 & 62.6 & 9.0 & 12.1 & 32 & 69.1 & 17.0 & 13.8 \\
\hline 90 & 273 & 50.7 & 4.7 & 14.1 & 503 & 51.4 & 11.5 & 16.6 \\
\hline 120 & 487 & 48.7 & 3.5 & 14.4 & 983 & 47.4 & 10.0 & 17.3 \\
\hline 150 & 800 & 47.6 & 2.9 & 14.4 & 1400 & 43.5 & 5.9 & 16.6 \\
\hline
\end{tabular}

where $\mathrm{BL}$ is black liquor

Lower pulp yields were obtained for hardwood at the beginning of the process. Specifically, the total pulp yield of sweetgum after $30 \mathrm{~min}(0 \mathrm{H}$-factor; i.e. when the target temperature has not yet been reached) was $85.5 \%$, whereas, for pine, it was $93.2 \%$. The greater yield losses in sweetgum are because hardwoods are easier to pulp than softwoods, due to the former's lower lignin content and presence of syringyl units (Santos et al. 2011). In addition, at the beginning of conventional kraft cooking, xylan (main hemicellulose in 
hardwoods) is partly solubilized in the cooking liquor and many of the side groups and acetic acid residues are cleaved (Viikari et al. 2009). On the other hand, after $150 \mathrm{~min}$, the pulp yield for sweetgum and pine were $47.6 \%$ (800 H-factor) and 43.5\% (1400 H-factor), respectively. Even though initially sweetgum showed greater pulp yield losses, the final pulp yield was superior to pine also because of the relative ease in pulping hardwood compared to pine. Harsher pulping conditions were necessary to obtain pine pulp due to higher starting lignin content, which explains the lower yield.

The effective alkali $\left(\operatorname{as~}_{2} \mathrm{O}\right)$ for the sweetgum and pine cooks was $16 \%(20.5 \mathrm{~g} / \mathrm{L})$ and $19 \%(24.4 \mathrm{~g} / \mathrm{L})$ based upon O.D. wood, respectively, which accounts for most of the inorganics added to the process. A minor part of the inorganics was associated with the wood as Non-Process Elements (NPEs). The ions $\mathrm{OH}^{-}$and $\mathrm{HS}^{-}$are consumed by lignin and carbohydrate hydrolytic reactions; hence, the residual effective alkali (rEA) decreased over time. Within $150 \mathrm{~min}$, the rEA was $2.9 \mathrm{~g} / \mathrm{L}$ in the sweetgum black liquor $(800 \mathrm{H}$ factor) and $5.9 \mathrm{~g} / \mathrm{L}$ in the pine black liquor $(1400 \mathrm{H}$-factor).

The method used to determine solids content in the black liquor accounts for the organic and inorganic fractions present in the liquor; thus, an increase over the process was expected because of the degradation and dissolution of wood compounds. The solids ranged from $8.9 \%$ ( $0 \mathrm{H}$-factor) to $14.4 \%$ (800 $\mathrm{H}$-factor) in sweetgum and from $11.1 \%$ (0 $\mathrm{H}$-factor) to $16.6 \%$ (1400 $\mathrm{H}$-factor) in pine.

The goal of kraft pulping is to preserve the carbohydrates content as high as possible. Unfortunately, carbohydrates degrade as delignification reactions occur. The composition analysis of sweetgum and pine wood chips and pulps are shown in Table 4.

Table 4. Characterization of Sweetgum and Pine Wood Chips for Carbohydrates, Lignin and Ash at Time "O" Followed by their Resultant Pulps for All Other Times Throughout Kraft Pulping Of $100 \mathrm{~g}$ (O.D.) of Wood

\begin{tabular}{|c|c|c|c|c|c|c|c|c|c|}
\hline $\begin{array}{c}\text { Cook } \\
\begin{array}{c}\text { Time } \\
(\mathrm{min})\end{array}\end{array}$ & Cellulose & Xylan & Galactan & GM & $\begin{array}{c}\text { Total } \\
\text { Lignin }\end{array}$ & $\begin{array}{c}\text { Klason } \\
\text { Lignin }\end{array}$ & ASL & Ash \\
\cline { 2 - 10 } & \multicolumn{7}{|c|}{ Sweetgum } \\
\hline 0 & 43.5 & 14.8 & 1.2 & 5.1 & 25.9 & 23.5 & 2.4 & 0.4 \\
\hline 30 & 38.4 & 12.3 & 0.8 & 3.6 & 21.6 & 19.1 & 2.5 & 1.2 \\
\hline 60 & 36.0 & 9.9 & 0.7 & 1.2 & 10.8 & 9.5 & 1.3 & 0.8 \\
\hline 90 & 33.5 & 8.7 & 0.3 & 0.9 & 2.9 & 2.1 & 0.8 & 0.6 \\
\hline 120 & 33.5 & 8.5 & 0.3 & 0.9 & 1.4 & 0.8 & 0.7 & 0.6 \\
\hline 150 & 33.2 & 8.6 & 0.3 & 1.1 & 1.2 & 0.5 & 0.7 & 0.6 \\
\hline & & & & & & & \\
\hline 0 & 40.0 & 6.1 & 3.3 & 16.4 & 31.7 & 30.9 & 0.8 & 0.7 \\
\hline 30 & 38.7 & 5.8 & 2.3 & 14.6 & 28.7 & 28.1 & 0.6 & 1.8 \\
\hline 60 & 36.1 & 4.9 & 1.4 & 6.4 & 19.2 & 18.8 & 0.4 & 1.4 \\
\hline 90 & 35.1 & 3.6 & 1.0 & 6.2 & 6.7 & 6.3 & 0.4 & 0.9 \\
\hline 120 & 35.4 & 3.5 & 0.9 & 5.1 & 3.9 & 3.5 & 0.3 & 0.9 \\
\hline 150 & 32.8 & 3.4 & 0.7 & 4.6 & 3.3 & 3.0 & 0.3 & 0.7 \\
\hline
\end{tabular}

Where GM is glucomannan, Total Lignin is a sum of Klason Lignin (acid-insoluble lignin) and acidsoluble lignin (ASL). 
Time "zero" shows the characterization of the wood chips, while times 30 to 150 min are characterizations of the pulps produced. The residual carbohydrates content (i.e., cellulose, xylan, galactan, and glucomannan), lignin, and ash in the pulp were calculated based on the content measured and pulp yield. Thus, the characterization presented in Table 4 depicts the degradation of each wood compound over the entire kraft pulping process.

The degradation of the main wood compounds of sweetgum and pine are graphically represented in Fig. 3, where the values are the residual content (g) of lignin, cellulose, and hemicelluloses over the kraft pulping process.

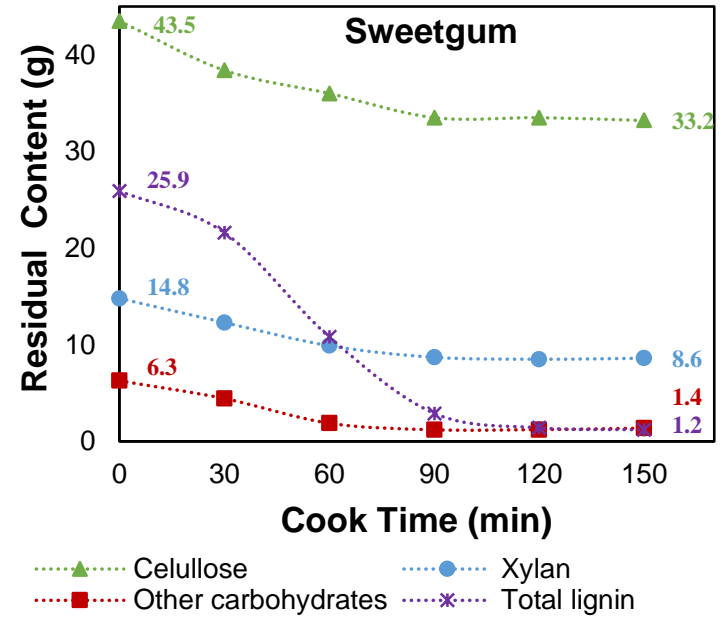

(a)

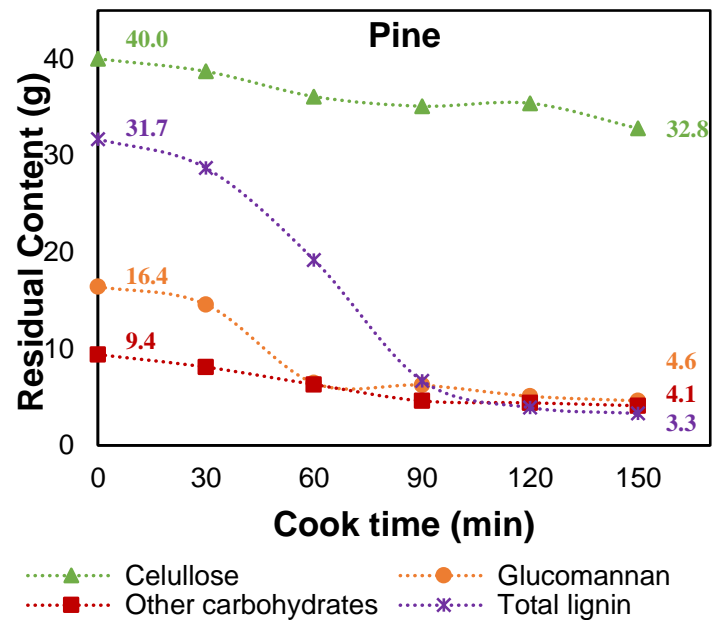

(b)

Fig. 3. Residual lignin and carbohydrate contents (g) for (a) sweetgum and (b) pine throughout kraft pulping of $100 \mathrm{~g}$ (O.D.) of wood

A large fraction of hemicellulose components are degraded and dissolved in the black liquor throughout kraft pulping; however, xylan (main hemicellulose in hardwoods) and glucomannan (main hemicellulose in softwoods) behave differently. The glucomannan is rapidly degraded and dissolved in the black liquor, whereas xylan is more resistant (Gellerstedt 2009). For instance, xylan contents of $14.8 \mathrm{~g}$ and $6.1 \mathrm{~g}$ were found in $100 \mathrm{~g}$ of sweetgum and pine wood chips, respectively. At the end of the pulping process, the residual amount in sweetgum was $8.6 \mathrm{~g}$, and in pine was $3.4 \mathrm{~g}$. The total loss of xylan was $41.6 \%$ in sweetgum and $44.3 \%$ in pine. With respect to glucomannan, the starting amount in sweetgum was $5.1 \mathrm{~g}$, whereas, in pine, it was $16.4 \mathrm{~g}$. After pulping, the final contents were $1.1 \mathrm{~g}$ and $4.6 \mathrm{~g}$ in sweetgum and pine, respectively. The total loss of glucomannan was $79 \%$ in sweetgum and $72 \%$ in pine. Thus, Fig. 3a shows how xylan is more resistant to the pulping process than the other hemicelluloses and Fig. $3 \mathrm{~b}$ shows how rapidly glucomannans are degraded through the process. Furthermore, in the early phases of kraft pulping, many of the xylan side groups are cleaved; these hydrolytic reactions consume alkali and contribute to carbohydrate loss (Viikari et al. 2009), which may account for the significant decrease in rEA (Table 1) and pulp yield (Fig. 3).

On the other hand, the loss of cellulose was less prominent in both raw materials. It is well known that cellulose is resistant to kraft pulping because of its packing (crystallinity). In contrast, hemicelluloses are much less uniformly arranged (more exposed) and thus heavily degraded during pulping (Viikari et al. 2009). The predominant carbohydrate degradation reaction, called endwise peeling, consists of successive depolymerization of the carbohydrates (starting from the reducing end group). At elevated 
temperatures (between 160 and $170{ }^{\circ} \mathrm{C}$ ), alkaline hydrolysis becomes important because it forms more reducing groups by the random cleavage of the glycosidic bonds in polysaccharides (Alén 2011b).

Moreover, cellulose has a much higher degree of polymerization than hemicelluloses (Sixta 2006). Thus, due to cellulose's higher molecular weight and crystalline structure, it is not as significantly degraded during the pulping process compared to the other carbohydrates. As a result, the retained carbohydrate yield of cellulose is significantly higher than that of the other carbohydrates (hemicelluloses). A cellulose loss of $23.7 \%$ was observed in sweetgum, whereas in pine the total loss was of $12.9 \%$.

The delignification process over kraft pulping occurs in three distinct phases (initial, bulk, and residual) (LéMon and Teder 1973). The main delignification reactions/removal occur over the first two phases. Up to $120 \mathrm{~min}$, approximately $97 \%$ of the sweetgum lignin was removed (487 $\mathrm{H}$-factor), while about $89 \%$ of pine lignin was removed (H-factor of 983). Even though the pulping conditions applied to pine were harsher than the conditions applied to sweetgum, the delignification of sweetgum was greater than pine, which reinforces the superior pulpability of hardwoods over softwoods. The residual phase, which is less selective towards lignin degradation, dominates after about 90 to $95 \%$ delignification (Sjödahl 2006). This phase was observed for both samples after approximately 20 min of cooking, in which less than $2 \%$ of lignin was removed.

\section{Lignin Precipitation and Characterization}

Two lignin fractions were precipitated from the black liquor generated; one was precipitated at $\mathrm{pH} 9.5$ and the other at $\mathrm{pH} 2.5$. Lignin precipitation is typically followed by filtration; however, due to its colloidal nature, the filtration step is a challenge. Complete or partial plugging of the filter cake has been reported, which requires large filter areas (Tomani 2010) and leads to high levels of impurities in the lignin (Öhman et al. 2007). The separation of the lignin from the black liquor was carried out by centrifugation to mitigate this problem for laboratory studies.

In the course of kraft pulping, lignin undergoes relatively drastic degradation reactions, for instance, cleavage of $\beta-\mathrm{O}-4$ linkage (main linkage in lignin), which results in the liberation of phenolic hydroxyl groups. These groups increase the hydrophilicity of lignin fragments (Hubbe et al. 2019) and lead to lignin dissolution in the black liquor. It has been determined that the protonation of the phenolic hydroxyl groups occurs over about $\mathrm{pH} 9$ to 11. So, with decreasing $\mathrm{pH}$ to this range, lignin solubility decreases, resulting in precipitation. In addition, further lowering $\mathrm{pH}$ to around 2, the carboxylic acid groups in lignin $\left(\mathrm{pK}_{\mathrm{a}} 3\right.$ to 5) are also protonated, which enhances precipitation (Alén 2011a). Therefore, lignin precipitation experiments are based on the concepts of pKa and protonation.

\section{Sweetgum analysis}

In addition to lignin, other degradation products are found in the black liquor that can also be co-precipitated with lignin as impurities. The characterization of wood chips and pulps has already been presented above; thus, it was possible to calculate the content of a given compound in the black liquor by the difference between its content in the wood and the pulp.

The material balance of the precipitation experiments for sweetgum is shown in Table 5. After pulping $100 \mathrm{~g}$ (O.D.) of wood chips, the solids in the black liquor were measured according to the standard "TAPPI/ANSI T $650 \mathrm{om}-15$ " protocol and converted 
to a weight basis. Since the two lignin fractions (at $\mathrm{pH} 9.5$ and 2.5) were obtained from the same black liquor sample, the solids in the black liquor presented in $\mathrm{pH} 2.5$ section are a subtraction of the solids originally found in the black liquor and the solids precipitated at $\mathrm{pH}$ 9.5. The lignin in the black liquor was calculated from the difference between the lignin content in the wood and the pulp, at a given time/H-factor.

It was observed that the solids in the black liquor increased as pulping progressed, which was due to degradation and dissolution of wood compounds. After 30 min of pulping (0 H-factor), $38.9 \mathrm{~g}$ of solids were found in the sweetgum black liquor, which were a mixture of organic and inorganic compounds. Out of the $38.9 \mathrm{~g}, 4.3 \mathrm{~g}$ were accounted for by the difference between the lignin content in the wood and in the pulp. After $150 \mathrm{~min}$ (800 $\mathrm{H}$-factor), an increased mass of solids was found (68.2 g,) and $24.7 \mathrm{~g}$ was accounted for by lignin.

Table 5. Material Balance of Lignin Precipitation from Sweetgum Black Liquors

\begin{tabular}{|c|c|c|c|c|c|c|c|c|c|}
\hline \multirow{2}{*}{$\begin{array}{c}\text { Cook } \\
\begin{array}{c}\text { Time } \\
(\mathrm{min})\end{array}\end{array}$} & $\begin{array}{c}\text { Solids in } \\
\text { the BL }\end{array}$ & $\begin{array}{c}\text { Lignin } \\
\text { in the } \\
\text { BL }\end{array}$ & $\begin{array}{c}\text { Solids } \\
\text { precipitated }\end{array}$ & Glucan & Xylan & $\begin{array}{c}\text { Total } \\
\text { Lignin }\end{array}$ & $\begin{array}{c}\text { Klason } \\
\text { Lignin }\end{array}$ & ASL & Ash \\
\hline \multicolumn{7}{|c|}{$\mathrm{pH} 9.5$} \\
\hline 30 & 38.9 & 4.3 & 0.6 & 0.1 & 0.3 & 0.1 & 0.1 & 0.0 & 0.0 \\
\hline 60 & 55.5 & 15.1 & 5.5 & 0.5 & 1.2 & 3.1 & 2.8 & 0.2 & 0.1 \\
\hline 90 & 66.2 & 23.0 & 12.4 & 0.7 & 1.3 & 9.0 & 8.4 & 0.6 & 0.3 \\
\hline 120 & 68.1 & 24.5 & 14.7 & 0.8 & 1.4 & 10.9 & 10.4 & 0.5 & 0.3 \\
\hline 150 & 68.2 & 24.7 & 12.3 & 0.5 & 1.1 & 9.4 & 9.1 & 0.3 & 0.3 \\
\hline & & & & & & & & & \\
\hline 30 & 38.3 & 4.2 & 0.8 & 0.0 & 0.2 & 0.3 & 0.3 & 0.0 & 0.0 \\
\hline 60 & 50.0 & 12.0 & 4.2 & 0.0 & 0.3 & 3.2 & 3.0 & 0.2 & 0.0 \\
\hline 90 & 53.8 & 14.0 & 3.6 & 0.0 & 0.1 & 3.2 & 3.0 & 0.2 & 0.0 \\
\hline 120 & 53.4 & 13.5 & 4.4 & 0.0 & 0.2 & 4.0 & 3.8 & 0.2 & 0.0 \\
\hline 150 & 55.9 & 15.3 & 8.4 & 0.0 & 0.4 & 7.8 & 7.5 & 0.3 & 0.1 \\
\hline
\end{tabular}

Weight based on pulping $100 \mathrm{~g}$ of wood chips. Where $\mathrm{BL}$ is black liquor, Total lignin is a sum of Klason lignin (acid-insoluble lignin) and acid-soluble lignin (ASL).

Furthermore, the total amount of solids precipitated (lignin, carbohydrates, and ash) by acidification increased over the process. After $30 \mathrm{~min}(0 \mathrm{H}$-factor), only $0.6 \mathrm{~g}$ were precipitated during the carbonation of the sweetgum black liquor (acidification to $\mathrm{pH} 9.5$ ), whereas at $120 \mathrm{~min}$ (487 $\mathrm{H}$-factor), $14.7 \mathrm{~g}$ were precipitated. The same trend was observed throughout the precipitation of the lignin fraction at $\mathrm{pH} 2.5$ (acidification with $\mathrm{HCl}$ ). This increase was expected since more organic compounds were found in the black liquor throughout the process due to hydrolytic reactions.

In general, at higher $\mathrm{pH}$, the fraction of lignin that precipitates has a higher molecular weight, whereas, at lower $\mathrm{pH}$, the lignin that precipitates has a lower molecular weight (García et al. 2009; dos Santos et al. 2014; Kumar et al. 2016). A decrease in the amount of lignin precipitated at $\mathrm{pH} 9.5$ between 120 to $150 \mathrm{~min}$ (487 and $800 \mathrm{H}$-factor, respectively) was observed, followed by an increase in the fraction obtained at $\mathrm{pH} 2.5$. This likely occurred due to further degradation of the lignin dissolved in the black liquor into 
smaller molecules and further lignin depolymerization over the pulping process.

Even though significant amounts of carbohydrates are not expected to precipitate with lignin, sweetgum lignins isolated at $\mathrm{pH} 9.5$ were heavily contaminated with carbohydrates. For instance, at $30 \mathrm{~min}$ ( $0 \mathrm{H}$-factor), $0.6 \mathrm{~g}$ of solids were isolated after carbonation, of which $0.1 \mathrm{~g}$ was glucan, and $0.3 \mathrm{~g}$ was xylan, whereas only $0.1 \mathrm{~g}$ was found to be lignin. On the other hand, the lignin isolated at $\mathrm{pH} 2.5$ showed superior purity, i.e., less carbohydrates and ash. It is well known that lignin precipitated at higher $\mathrm{pH}$ is less degraded (higher molecular weight); therefore, it can be safely assumed that the carbohydrates associated with these lignins are also less degraded (Zhu et al. 2015). Thus, at $\mathrm{pH}$ 9.5, the carbohydrates are less degraded, less soluble, and hence they can be

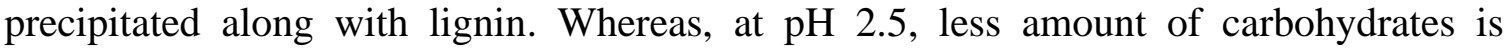
remaining, and they are more degraded/soluble and do not precipitate. Another possibility is the lignin and carbohydrates are chemically bonded (LCCs), which leads to precipitation of lignin and carbohydrates at the same time.

It is important to mention that higher lignin yields have been reported with straightforward filtration recovery when compared with centrifugal recovery; however, filtration takes a longer time due to the colloidal nature of the lignin precipitate (Namane et al. 2015).

Pine analysis and comparison with sweetgum

The present work intended to establish a baseline comparison between the precipitation of lignin from hardwood and softwood black liquors. Thus, the precipitation, characterization, and material balance for both hardwood and softwood black liquors were performed under similar operating conditions. The material balances for the precipitation experiments are shown in Table 5 for hardwood and Table 6 for pine.

Table 6. Material Balance of Lignin Precipitation from Pine Black Liquors

\begin{tabular}{|c|c|c|c|c|c|c|c|c|c|}
\hline \multirow[b]{2}{*}{$\begin{array}{l}\text { Cook } \\
\text { Time } \\
\text { (min) }\end{array}$} & \multicolumn{9}{|c|}{ Parameter (g) } \\
\hline & $\begin{array}{l}\text { Solids } \\
\text { in } \\
\text { the } B L\end{array}$ & $\begin{array}{l}\text { Lignin in } \\
\text { the } B L\end{array}$ & $\begin{array}{c}\text { Solids } \\
\text { precipitated }\end{array}$ & Glucan & Xylan & $\begin{array}{l}\text { Total } \\
\text { lignin }\end{array}$ & $\begin{array}{l}\text { Klason } \\
\text { Lignin }\end{array}$ & ASL & Ash \\
\hline \multicolumn{10}{|c|}{$\mathrm{pH} 9.5$} \\
\hline 30 & 47.7 & 3.0 & 0.4 & 0.0 & 0.0 & 0.3 & 0.3 & 0.0 & 0.0 \\
\hline 60 & 62.8 & 12.4 & 4.6 & 0.0 & 0.0 & 4.3 & 4.2 & 0.0 & 0.1 \\
\hline 90 & 78.4 & 25.0 & 6.9 & 0.0 & 0.2 & 6.4 & 6.2 & 0.2 & 0.1 \\
\hline 120 & 82.7 & 27.8 & 19.4 & 0.0 & 0.4 & 16.4 & 16.1 & 0.4 & 0.4 \\
\hline 150 & 83.0 & 28.4 & 21.0 & 0.0 & 0.4 & 19.4 & 19.0 & 0.4 & 0.5 \\
\hline \multicolumn{10}{|c|}{$\mathrm{pH} 2.5$} \\
\hline 30 & 47.3 & 2.7 & 1.2 & 0.0 & 0.0 & 1.0 & 1.0 & 0.0 & 0.0 \\
\hline 60 & 58.2 & 8.1 & 3.0 & 0.0 & 0.0 & 2.6 & 2.6 & 0.1 & 0.0 \\
\hline 90 & 71.5 & 18.6 & 16.9 & 0.0 & 0.5 & 13.9 & 13.5 & 0.5 & 0.2 \\
\hline 120 & 63.3 & 11.4 & 9.0 & 0.0 & 0.3 & 7.6 & 7.3 & 0.2 & 0.1 \\
\hline 150 & 62.0 & 9.0 & 7.1 & 0.0 & 0.2 & 6.4 & 6.2 & 0.2 & 0.1 \\
\hline
\end{tabular}

Where $\mathrm{BL}$ is black liquor, Total lignin is a sum of Klason lignin (acid-insoluble lignin) and acidsoluble lignin (ASL). 
During the pulping of pine, the solids content of black liquor increased, which is in accordance with the sweetgum experiments. After $30 \mathrm{~min}$ of the pulping of $100 \mathrm{~g}$ (O.D.) of pine wood chips ( $0 \mathrm{H}$-factor), $47.7 \mathrm{~g}$ of solids were found in the black liquor (organic and inorganic); while after $150 \mathrm{~min}$ (1400 $\mathrm{H}$-factor), $83.0 \mathrm{~g}$ of solids were found. The solids content at $30 \mathrm{~min}(0 \mathrm{H}$-factor) was reasonably higher in pine black liquor ( $47.7 \mathrm{~g})$ than in sweetgum (38.9 g). This surplus of solids has an inorganic origin (white liquor) since the alkali charge was greater, and not much degradation was observed in the pulped pine chips at this point.

The total amount of solids precipitated from pine black liquor increased over the process, which is also in accordance with the sweetgum experiments. After $30 \mathrm{~min}$ of pulping ( $0 \mathrm{H}$-factor), $0.4 \mathrm{~g}$ of solids were obtained at $\mathrm{pH} 9.5$, whereas at $150 \mathrm{~min}(1400 \mathrm{H}$ factor), same $\mathrm{pH}$, the recovery was $21 \mathrm{~g}$. In addition, the purity of the pine lignin was superior to the sweetgum lignin due to less carbohydrate and ash contamination. For instance, the total solids precipitated over the carbonation of sweetgum black liquor obtained at the end of the pulping process ( $800 \mathrm{H}$-factor, $150 \mathrm{~min}$ ) was $12.3 \mathrm{~g}$, where about $1.9 \mathrm{~g}$ was contamination (carbohydrates and ash). On the other hand, out of the $21 \mathrm{~g}$ of solids obtained at the end of the pulping of pine wood chips (1400 H-factor, $150 \mathrm{~min})$, only around $0.9 \mathrm{~g}$ were accounted for by contamination. In addition, the increase in lignin recovery throughout the pulping process could also be explained by lignin concentration. In low lignin concentration samples, the lignin molecules are surrounded by significantly more water molecules than in high lignin concentration samples, which might influence lignin interactions/agglomerations (Helander et al. 2016) and hence affect lignin recovery. The results of lignin concentration are not shown; however the same liquor to wood ratio was applied to all pulping experiments and the collected black liquors were evaporated to $20 \%$ solids content. Thus, a higher lignin content in the black liquor translates to higher lignin concentration.

Overall, it was observed that the precipitation of the lignin fraction at $\mathrm{pH} 2.5$ contributed to a considerable increase in lignin recovery (Fig. 4). This is in agreement with earlier investigations, which have shown that yield of precipitated lignin increased by decreasing pH (García et al. 2009; Theliander 2010; dos Santos et al. 2014; Zhu et al. 2014; Sewring et al. 2019).

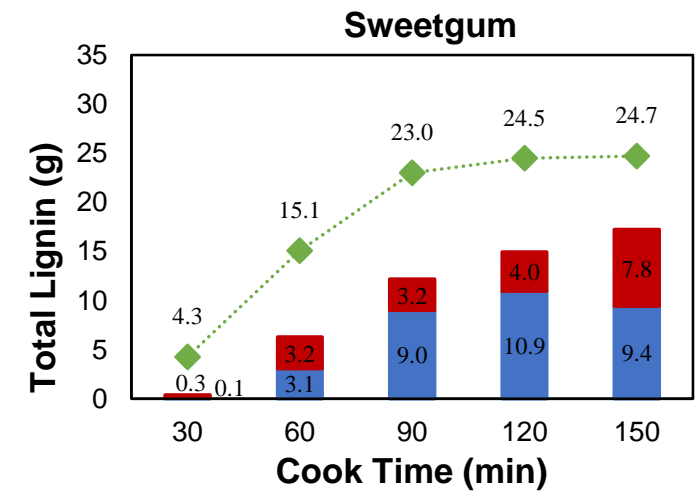

(a)

Total lignin precipitated at $\mathrm{pH} 2.5$

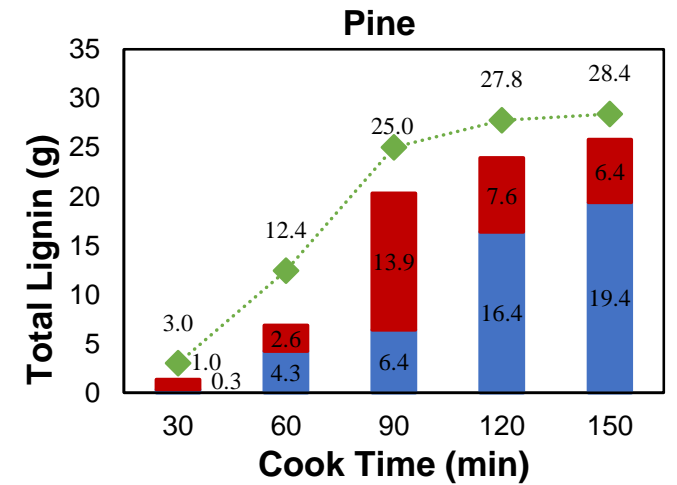

(b)

Fig. 4. Total lignin content in the black liquor and Total lignin precipitated at $\mathrm{pH} 9.5$ and 2.5 from (a) sweetgum and (b) pine samples throughout kraft pulping

Jardim et al. (2020). "Lignin precipitation: HW vs. SW," BioResources 15(3), 5464-5480. 5475 
At the onset of the pulping, the yield of lignin fraction obtained at $\mathrm{pH} 2.5$ was higher than the lignin fraction recovered at $\mathrm{pH}$ 9.5. It has been reported that lignin with high molecular weight precipitates at pHs around 8 to 11 , and lignin with low molecular weights precipitate at lower pH (dos Santos et al. 2014; Kumar et al. 2016). In addition, it is known that mainly low molecular weight lignin is removed during the initial phase of delignification (Gellerstedt and Lindfors 1984). As the kraft pulping continues, lignin fractions of higher molecular weight are removed and solubilized in the black liquor (Gellerstedt et al. 1984). Moreover, it is known that condensation of lignin fragments occurs by repolymerization during the pulping process, causing an increase in the molecular weight as the process continues (Shrotri et al. 2017). Therefore, initially, more lignin is obtained at $\mathrm{pH} 2.5$ than at $\mathrm{pH} 9.5$, and as the pulping proceeds, the yield of lignin obtained at $\mathrm{pH} 9.5$ increases, while yield at $\mathrm{pH} 2.5$ drops.

As softwood lignin precipitation methods have been well documented in both the literature and in commercial practice, it was assumed that those methods could be used as a template for hardwood lignin precipitation. However, this study showed that the behavior of sweetgum and pine lignin as a function of precipitation was considerably different. Firstly, the recovery of lignin from pine black liquors was greater than the recovery from sweetgum black liquor; which is in accordance with previous investigations that claims superior yields from softwoods over hardwoods (Öhman et al. 2007; Santos et al. 2011; 2012; Zhu et al. 2014, 2015). Furthermore, Table 7 depicts the percentage of carbohydrates and lignin recovered via precipitation at both $\mathrm{pH} 9.5$ and 2.5. As shown in the table, significant quantities of the sweetgum carbohydrates were precipitated, and relatively lower levels of lignin were obtained. For the pine liquor, only low amounts of the carbohydrates present in the black liquor were isolated with lignin via precipitation. For both the sweetgum and pine, the percentage of lignin precipitated increased as the cook progressed, but much superior lignin yields were obtained for the pine liquors at all conditions evaluated.

Table 7. Percentage of Carbohydrates and Lignin Precipitated from the Collected Sweetgum and Pine Black Liquors throughout the Cooking Process

\begin{tabular}{|c|c|c|c|c|}
\hline \multirow{2}{*}{$\begin{array}{c}\text { Cook } \\
\text { Time } \\
(\mathrm{min})\end{array}$} & \multicolumn{2}{|c|}{ Sweetgum } & \multicolumn{2}{c|}{ Pine } \\
\cline { 2 - 5 } & Carbohydrates (\%) & Total Lignin (\%) & $\begin{array}{c}\text { Carbohydrates } \\
(\%)\end{array}$ & Total Lignin (\%) \\
\hline 30 & 6.6 & 9.3 & 0.5 & 45.5 \\
\hline 60 & 12.2 & 41.8 & 0.6 & 55.4 \\
\hline 90 & 10.1 & 52.9 & 4.0 & 81.4 \\
\hline 120 & 11.2 & 61.1 & 3.7 & 86.2 \\
\hline 150 & 9.5 & 69.7 & 2.5 & 90.9 \\
\hline
\end{tabular}

The total lignin recovery presented in Table 7 was calculated based on the sum of the amount of lignin precipitated at $\mathrm{pH} 9.5$ and 2.5 divided by the calculated lignin content in the black liquor. The maximum lignin recovery was obtained from black liquor samples generated at the end of the kraft pulping process. The total lignin recovery of sweetgum was $69.7 \%$ (800 H-factor), whereas the total lignin recovery of pine was $90.9 \%(1400 \mathrm{H}-$ factor). Overall, the yield of lignin obtained from pine was greater than from sweetgum, mainly because part of the sweetgum lignin remained soluble in the supernatant due to the contamination with carbohydrates. The percentage of carbohydrates precipitated was calculated based on the amount of carbohydrates measured in the lignin fractions $(\mathrm{pH} 9.5$

Jardim et al. (2020). "Lignin precipitation: HW vs. SW," BioResources 15(3), 5464-5480. 5476 
and 2.5), and the amount dissolved in the black liquor, which could be obtained by the difference between the residual content of carbohydrates in the produced pulp and the content in the black liquor.

The presence of lignin-carbohydrate complexes (LCCs) is a plausible explanation for the low yields achieved by sweetgum. Although these linkages exist in small amounts in lignocellulosic materials, it is speculated that almost all lignin is associated with polysaccharides (Lawoko et al. 2005; Du et al. 2013). The multiple - OH groups from carbohydrates will contribute to hydrophilicity, rendering the lignin more soluble in water (Hubbe et al. 2019). In addition, the LCCs are suggested to play a crucial role in recalcitrance during biomass processing and fractionation (Giummarella et al. 2019). For the analyses performed so far, it cannot be claimed that the carbohydrates that were precipitated with the sweetgum lignin were chemically bonded to it; however, it is plausible that they were chemically associated. Indeed, considerably more carbohydrates were detected in the sweetgum lignin versus pine. Moreover, the greater loss of cellulose by sweetgum during the kraft pulping might also be related to this association between carbohydrates and lignin. In addition, incorporation of xylan into lignin agglomerates as they form could cause a reduction in the further growth/agglomeration of particles due to increased electrostatic repulsive forces and/or steric effects, resulting in smaller particles being formed when compared to less xylan in the system (Sewring et al. 2019).

\section{CONCLUSIONS}

1. Lignin recovery from black liquor and lignin purity increased with the increase of $\mathrm{H}$ factor. The recovery at $\mathrm{pH} 2.5$ was higher at the beginning of the process; however, as pulping proceeded, the recovery at $\mathrm{pH} 9.5$ increased, while at $\mathrm{pH} 2.5$, it decreased.

2. The recovery of sweetgum lignin (hardwood) showed low yields since considerable levels were still soluble in the black liquor after acidification. In addition, these lignins presented low purity due to high contamination with carbohydrates.

3. Pine lignin (softwood) was more easily precipitated and displayed superior purity.

4. All lignin precipitated at $\mathrm{pH} 2.5$ were purer than the fraction obtained at $\mathrm{pH} 9.5$, and the former fraction contributed to a considerable recovery enhancement.

5. The total recovery of the sweetgum lignin (summing both fractions) was $69.7 \%$ at 150 $\min (800 \mathrm{H}$-factor), whereas for pine was $90.2 \%$ at $150 \mathrm{~min}$ (1400 $\mathrm{H}$-factor).

6. Overall, the recovery of pine lignin was superior to the recovery of sweetgum lignin with respect to yield and purity.

\section{ACKNOWLEDGMENTS}

The authors are grateful for technical and funding support from WestRock. 


\section{REFERENCES CITED}

Akiyama, T., Goto, H., Nawawi, D. S., Syafii, W., Matsumoto, Y., and Meshitsuka, G. (2005). "Erythro/threo ratio of $\beta$-O-4-structures as an important Structural characteristic of lignin. Part 4: Variation in the erythro/threo ratio in softwood and hardwood lignins and its relation to syringyl/guaiacyl ratio," Holzforschung 59(3), 276-281. DOI: 10.1515/HF.2005.045

Alén, R. (2000). "Structure and chemical composition of wood," in: Forest Products Chemistry, P. Stenius, (ed.), Fapet Oy, Helsinki, Finland, pp. 11-57.

Alén, R. (2011a). "Principles in biorefining," in: Biorefining of Forest Resources, Paperi ja Puu Oy, Helsinki, Finland, pp. 55-114.

Alén, R. (2011b). "Structure and chemical composition of biomass feedstocks," in: Biorefining of Forest Resources, Paperi ja Puu Oy, Helsinki, Finland, pp. 18-54.

Dessbesell, L., Paleologou, M., Leitch, M., Pulkki, R., and Xu, C. (Charles). (2020). "Global lignin supply overview and kraft lignin potential as an alternative for petroleum-based polymers," Renewable and Sustainable Energy Reviews 123(February), article no. 109768. DOI: 10.1016/j.rser.2020.109768

Du, X., Gellerstedt, G., and Li, J. (2013). "Universal fractionation of lignin-carbohydrate complexes (LCCs) from lignocellulosic biomass: An example using spruce wood," The Plant Journal 74(2), 328-338. DOI: 10.1111/tpj.12124

Durruty, J., Mattsson, T., and Theliander, H. (2017). "Local filtration properties of Kraft lignin: The influence of residual xylan," Separation and Purification Technology 179, 455-466. DOI: 10.1016/j.seppur.2017.01.068

Fatehi, P., and Chen, J. (2016). "Extraction of technical lignins from pulping spent liquors, challenges and opportunities," in: Production of Biofuels and Chemicals from Lignin, Z. Fang , R. L. Smith, Jr., (eds.), Springer, Singapore. DOI: 10.1007/978-98110-1965-4_2

García, A., Toledano, A., Serrano, L., Egüés, I., González, M., Marín, F., and Labidi, J. (2009). "Characterization of lignins obtained by selective precipitation," Separation and Purification Technology 68(2), 193-198. DOI: 10.1016/j.seppur.2009.05.001

Gellerstedt, G. (2009). "Chemistry of chemical pulping," in: Pulp and Paper Chemistry and Technology, M. Ek, G. Gellerstedt (eds.), De Gruyter, Berlin, Germany, pp. 91120.

Gellerstedt, G., Lindfors, E.-L., Lapierre, C., and Monties, B. (1984). "Structural changes in lignin during kraft cooking. Part 2. Characterization by acidolysis," Svensk Papperstidn 87(9), 61.

Gellerstedt, G., and Lindfors, E. L. (1984). "Structural changes in lignin during kraft pulping," Holzforschung 38(3), 151-158. DOI: 10.1515/hfsg.1984.38.3.151

Giummarella, N., Pu, Y., Ragauskas, A. J., and Lawoko, M. (2019). “A critical review on the analysis of lignin carbohydrate bonds," Green Chemistry 21(7), 1573-1595. DOI: $10.1039 / \mathrm{c} 8 \mathrm{gc0} 03606 \mathrm{c}$

Gomes, V. J., Jameel, H., Chang, H. M., Narron, R., Colodette, J., and Hart, P. W. (2018). "Effects of lignin chemistry on oxygen delignification performance," TAPPI Journal 17(7), 373-381. DOI: 10.32964/tj17.07.373

Helander, M., Mattsson, T., Theliander, H., and Lindström, M. E. (2016). "Parameters affecting the cross-flow filtration of dissolved LignoBoost kraft lignin," Journal of Wood Chemistry and Technology 36(1), 1-8. DOI: 10.1080/02773813.2015.1025284

Howell, J. F., and Thring, R. W. (2000). "Hardwood lignin recovery using generator 
waste acid. Statistical analysis and simulation," Industrial and Engineering Chemistry Research 39(7), 2534-2540. DOI: 10.1021/ie990190q

Hubbe, M. A., Alén, R., Paleologou, M., Kannangara, M., and Kihlman, J. (2019). "Lignin recovery from spent alkaline pulping liquors using acidification, membrane separation, and related processing steps: A review," BioResources 14(1), 2300-2351. DOI: 10.15376/biores.14.1.2300-2351

Klett, A. S. (2017). Purification, Fractionation, and Characterization of Lignin from Kraft Black Liquor for Use as a Renewable Biomaterial, PhD Dissertation, Clemson University, Clemson, SC, USA.

Kumar, H., Alén, R., and Sahoo, G. (2016). "Characterization of hardwood soda-AQ lignins precipitated from black liquor through selective acidification," BioResources 11(4), 9869-9879. DOI: 10.15376/biores.11.4.9869-9879

Lawoko, M., Henriksson, G., and Gellerstedt, G. (2005). "Structural differences between the lignin-carbohydrate complexes present in wood and in chemical pulps," Biomacromolecules 6(6), 3467-3473. DOI: 10.1021/bm058014q

LéMon, S., and Teder, A. (1973). "Kinetics of the delignification in kraft pulping, Part 1. Bulk delignification of pine," Svensk Papperstidn 76(11), 407-414.

Lin, S. Y., and Dence, C. W. (1992). Methods in Lignin Chemistry, Springer-Verlag, Heidelberg, Germany.

Magdeldin, M., and Järvinen, M. (2020). "Supercritical water gasification of Kraft black liquor: Process design, analysis, pulp mill integration and economic evaluation," Applied Energy 262(January), article no. 114558. DOI:

10.1016/j.apenergy.2020.114558

Miller, J., Faleiros, M., and Pilla, L. (2016). Lignin: Technology, Applications, and Markets, RISI, Inc., Bedford, MA.

Namane, M., Sithole, B. B., and Ramjugernath, D. (2015). "Centrifugal washing and recovery as an improved method for obtaining lignin precipitated from South African kraft mill black liquor," Journal of Scientific and Industrial Research 74(10), 571576.

Öhman, F., Wallmo, H., and Theliander, H. (2007). "Precipitation and filtration of lignin from black liquor of different origin," Nordic Pulp \& Paper Research Journal 22(2), 188-193. DOI: 10.3183/npprj-2007-22-02-p188-193

Ralph, J., Lundquist, K., Brunow, G., Lu, F., Kim, H., Schatz, P. F., Marita, J. M., Hatfield, R. D., Ralph, S. A., Christensen, J. H., and Boerjan, W. (2004). "Lignins: Natural polymers from oxidative coupling of 4-hydroxyphenyl- propanoids," Phytochemistry Reviews 3(1-2), 29-60. DOI: 10.1023/B:PHYT.0000047809.65444.a4

dos Santos, P. S. B. do., Erdocia, X., Gatto, D. A., and Labidi, J. (2014). "Characterisation of kraft lignin separated by gradient acid precipitation," Industrial Crops and Products 55, 149-154. DOI: 10.1016/j.indcrop.2014.01.023

Santos, R. B., Capanema, E. A., Balakshin, M. K., Chang, H., and Jameel, H. (2011). "Effect of hardwoods characteristics on kraft pulping process: Emphasis on lignin structure," BioResources 6(4), 3623-3637. DOI: 10.15376/biores.6.4.3623-3637

Santos, R. B., Capanema, E. A., Balakshin, M. Y., Chang, H. M., and Jameel, H. (2012). "Lignin structural variation in hardwood species," Journal of Agricultural and Food Chemistry 60(19), 4923-4930. DOI: 10.1021/jf301276a

Sarkanen, K. V., Chang, H. M., and Allan, G. G. (1967). "Species variation in lignins III," TAPPI Journal 50(12), 587. 
Sewring, T., Durruty, J., Schneider, L., Schneider, H., Mattsson, T., and Theliander, H. (2019). "Acid precipitation of kraft lignin from aqueous solutions: The influence of pH, temperature, and xylan," Journal of Wood Chemistry and Technology 39(1), 113. DOI: $10.1080 / 02773813.2018 .1488870$

Shrotri, A., Kobayashi, H., and Fukuoka, A. (2017). "Catalytic conversion of structural carbohydrates and lignin to chemicals," in: Advances in Catalysis, C. Song, (ed.), Elsevier Inc, Amsterdam, Netherlands, pp. 59-123.

Sixta, H. (2006). Handbook of Pulp, Wiley-VCH, Weinheim, Germany.

Sjödahl, R. G. (2006). Some Aspects on the Effects of Dissolved Wood Components in Kraft Pulping, PhD Dissertation, KTH Royal Institute of Technology, Stockholm, Sweden.

Theliander, H. (2010). "The lignoboost process: Solubility of lignin," International Chemical Recovery Conference, Williamsburg, VA, 2, pp. 33-42.

Tomani, P. (2010). "The lignoboost process," Cellulose Chemistry and Technology 44(13), 53-58.

Viikari, L., Suurnäkki, A., Grönqvist, S., Raaska, L., and Ragauskas, A. (2009). "Forest products: Biotechnology in pulp and paper processing," in: Encyclopedia of Microbiology, M. Schaechter (ed.), Academic Press, Cambridge, MA. DOI: 10.1016/b978-012373944-5.00123-1

Wallmo, H., Littorin, A., Karlsson, H., Lindholm, K., Stern, R., and Christiansen, G. (2016). "The evolution of LignoBoost technology and the lignin bioproducts market Part 2," in: IBBC International Bioenergy \& Bioproducts Conference, Jacksonville, FL.

Wallmo, H., Richards, T., and Theliander, H. (2009). "An investigation of process parameters during lignin precipitation from kraft black liquors : A step towards an optimised precipitation operation," Nordic Pulp and Paper Research Journal 24, 158164. DOI: 10.3183/NPPRJ-2009-24-02-p158-164

Zhu, W., Westman, G., and Theliander, H. (2014). "Investigation and characterization of lignin precipitation in the lignoboost process," Journal of Wood Chemistry and Technology 34(2), 77-97. DOI: 10.1080/02773813.2013.838267

Zhu, W., Westman, G., and Theliander, H. (2015). "The molecular properties and carbohydrate content of lignins precipitated from black liquor," Holzforschung 69(2), 143-152. DOI: $10.1515 / \mathrm{hf}-2014-0062$

Article submitted: April 7, 2020; Peer review completed: May 16, 2020; Revised version received and accepted: May 20, 2020; Published: May 27, 2020.

DOI: 10.15376/biores.15.3.5464-5480 